\title{
Suživot vizualne kulture i povijesti umjetnosti: vizualna kultura kao međupredmetna tema
}

Skender, Lana

Source / Izvornik: Institucije povijesti umjetnosti : zbornik 4. kongresa hrvatskih povjesničara umjetnosti, 2019, 181 - 186

Conference paper / Rad u zborniku

Publication status / Verzija rada: Published version / Objavljena verzija rada (izdavačev PDF)

https://doi.org/10.31664/z4khpu.25

Permanent link / Trajna poveznica: https://urn.nsk.hr/urn:nbn:hr:254:329278

Rights / Prava: Attribution 4.0 International/Imenovanje 4.0 međunarodna

Download date / Datum preuzimanja: 2023-04-26

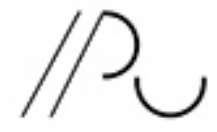

INSIITUTRZ POVIJESTUMJETNOST
Repository / Repozitorij:

PODEST - Institute of Art History Repository

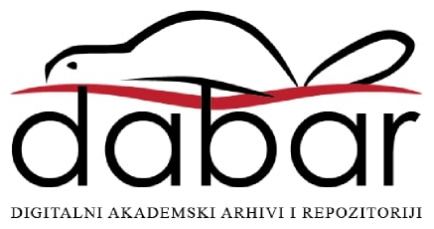




\section{Suživot vizualne kulture i povijesti umjetnosti: vizualna kultura kao međupredmetna tema}

\section{Suvremene inicijative u umjetničkom obrazovanju}

U posljednje vrijeme svjedoci smo inicijativa za promjene u podučavanju predmeta iz umjetničkog područja, koje bi obuhvaćale ne samo konceptualne promjene pristupa učenju i poučavanju predmeta Likovna umjetnost ${ }^{1}$ već i promjenu sama naziva predmeta, koji bi se preimenovao u Vizualnu kulturu, ${ }^{2}$ što je pak prepoznato kao prijetnja položaju povijesti umjetnosti u obrazovnim sustavima. Vizualna kultura, disciplina uvelike podudarna s tzv. znanošću o slici, kako glasi naziv discipline koja okuplja srodna istraživanja u akademskoj praksi njemačkoga govornog područja, usmjerena je istraživanju pojava i značenja slike koji nisu nužno povezani s umjetničkim stvaranjem, već s njezinom reprezentacijskom moći u prenošenju poruka i ideologija. Interes za promjenu javio se prije svega zbog reformi europskih i svjetskih kurikula koji teže holističkom pristupu, u kojima je najvažnije stjecanje znanja i kompetencija potrebnih za život u sadašnjosti i budućnosti, dok su tradicionalni kurikuli usmjereni znanjima o prošlosti bez njihove izravne primjene u sadašnjem trenutku. Postmoderno doba obilježeno je ikoničkim obratom, odnosno proširenjem komunikacijske paradigme u kojoj slika postaje generalni konstruktor kulture i glavno komunikacijsko oruđe. ${ }^{3}$ Načini reprezentacije i procesi ideologizacije ponuđeni kroz sliku postali su zanimljivi umjetničkim praksama druge polovine 2o. stoljeća, koje se okreću kritičkom propitivanju različitih kulturnih fenomena i masovnih medija, ${ }^{4}$ stvarajući jake temelje za ugrađivanje vizualne kulture u koncepte podučavanja i učenja predmeta Likovna umjetnost. Time se dovela u pitanje učinkovitost učenja o umjetnosti, u višim obrazovnim ciklusima, isključivo prema povijesnom pristupu gdje je glavni cilj razumijevanje umjetničkog djela u kontekstu vremena u kojem nastaje, a glavna učenička kompetencija razlikovanje stilskih razdoblja. U većini europskih kurikula provedena je konceptualna promjena u pristupu sadržajima likovne umjetnosti, prije svega napuštanjem povijesne paradigme koja

\section{Lana Skender}

Odsjek za vizualne i medijske umjetnosti Akademija za umjetnost i kulturu u Osijeku Sveučilište Josipa Jurja Strossmayera u Osijeku lanaskndr@gmail.com

https://orcid.org/oooo-ooo2-6666-I325
I U Europi i svijetu koristi se naziv Vizualna umjetnost, a u Hrvatskoj Likovna umjetnost.

2 PAUL DUNCUM, Art Education for New Times, $u$ : Studies in Art Education. A Journal of Issues and Research, 38, 2 (I997.), 69-79, 69; KERRY FREEDMAN, Images That Transform: Analyzing Visual Culture That Changes People's Minds, u: Anadolu Journal of Educational Sciences International, Art Education Special Issue, November (20I5.), 27-32, 28.

3 W. J. T MITCHELL, What Do Pictures Want? The Lives and Loves of Images, Chicago, University of Chicago Press, 2005., 336-357, 337; esej „Showing Seeing: A Critique of Visual Culture" [2002.]; u hrvatskome prijevodu u: Tvrda, I-2 (2007.).

4 KERRY FREEDMAN, PATRICIA STUHR, Curriculum Change for the 2ist Century: Visual Culture in Art Education, $\mathrm{u}$ : Handbook of Research and Policy in Art Education, (ur.) Elliot W. Eisner i Michael D. Day, London, 2004., 8I5-828, 820 . 
onemogućava stvaranje izravnih veza između umjetničkih pojava u prošlosti i sadašnjosti. Sadržaji se usmjeravaju na problemske teme koje omogućavaju skokove kroz povijest i istraživanje različitih konteksta umjetničkih djela, od kojih su povijesni i stilski samo jedna od mogućnosti. Zbog obogaćivanja umjetničkih praksi 20. stoljeća postupcima i narativima koji potječu iz medija popularne kulture postalo je nužno proširenje područja podučavanja sa samih artefakata na široku primjenu slika u okolišu. Umjetnicima popularna kultura nije samo vizualni poticaj. Nameće se stoga nužnim učenika suočavati s različitom funkcijom slika u stvarnosti, upućujući na veze i razlike između komercijalnih slika i umjetničkih djela. Takva širina pristupa slici neće dovesti do poistovjećivanja umjetničkih djela i komercijalne produkcije slika, nego će jače osvijestiti razlike i potaknuti razumijevanje mehanizama komunikacije. ${ }^{5}$ Interpretiranje značenja širokog spektra slika zahtijeva pak novi pristup teoretiziranju slike, koji se ne oslanja samo na povijesnoumjetničku hermeneutiku, metodama usmjerenu na istraživanje značenja u domeni autorove namjere, nego se mora proširiti i na nenamjerna značenja koja nastaju u procesu promatranja. Svakako bi u interpretaciju slika trebalo uključiti istraživanje njihove uloge u konstrukciji kulturnih i osobnih identiteta, potom njihovu uvjetovanost konceptom individualnog autorstva te kritičku refleksiju spram efekata slika općenito. Time bi se ojačale interdisciplinarne veze između različitih područja, koje slici daju sociološku komponentu i povezuju je sa sadašnjim trenutkom, te se zadovoljavaju potrebe suvremenoga promatrača koji se susreće s različitim vizualnim izazovima, od kojih su samo neki umjetnička djela. Većina reformiranih kurikula ugradila je stoga sadržaje vizualne kulture u koncept predmeta Likovna umjetnost smatrajući baš taj predmet izvrsnom osnovom za razvoj promatračkih kompetencija.

\section{Područja istraživanja povijesti umjetnosti i vizualne kulture}

Osnovne bojazni o istiskivanju povijesti umjetnosti iz obrazovnih sustava utemeljene su na činjenici da se područja istraživanja vizualne kulture i povijesti umjetnosti ne podudaraju u potpunosti. Povijest umjetnosti proučava oblike artefakata koji imaju status umjetničkih djela ${ }^{6}$ i bavi se rekonstrukcijama njihova povijesnog identiteta, ${ }^{7}$ dok vizualna kultura obuhvaća široke aspekte primjene slike kao važnog medijatora u procesu komunikacije te se bavi njezinim utjecajem na promatrača bez tendencija stvaranja razlike između akademske umjetnosti i tvorevina popularne kulture (sl. I).

Vizualni komunikacijski proces u prijenosu značenja obuhvaća sve relacijske odnose između autora, umjetničkog djela ili vizualnog konstrukta i promatrača kao krajnjeg recipijenta. Relacijama između autora i umjetničkog djela bavi se znanost o umjetnosti, koja istražuje kreativan i tehnološki proces umjetničkog rada, koncept individualnog autorstva i
W. J. T. MITCHELL, Pokazati gledati [2002.], Turda, I-2 (2007.), 3I.

6 MARTIN WARNKE, Predmetna područja povijesti umjetnosti, u: Uvod u povijest umjetnosti [I986.], (ur.) Hans Belting i dr., Zagreb, Fraktura, 2007., I9-4I, I9.

7 WILLIBALD SAUERLÄNDER, Općenito utvrđivanje predmeta, u: Uvod u povijest umjetnosti [I986.], (ur.) Hans Belting i dr., Zagreb, Fraktura, 2007., II $3^{-137}$, II3. 


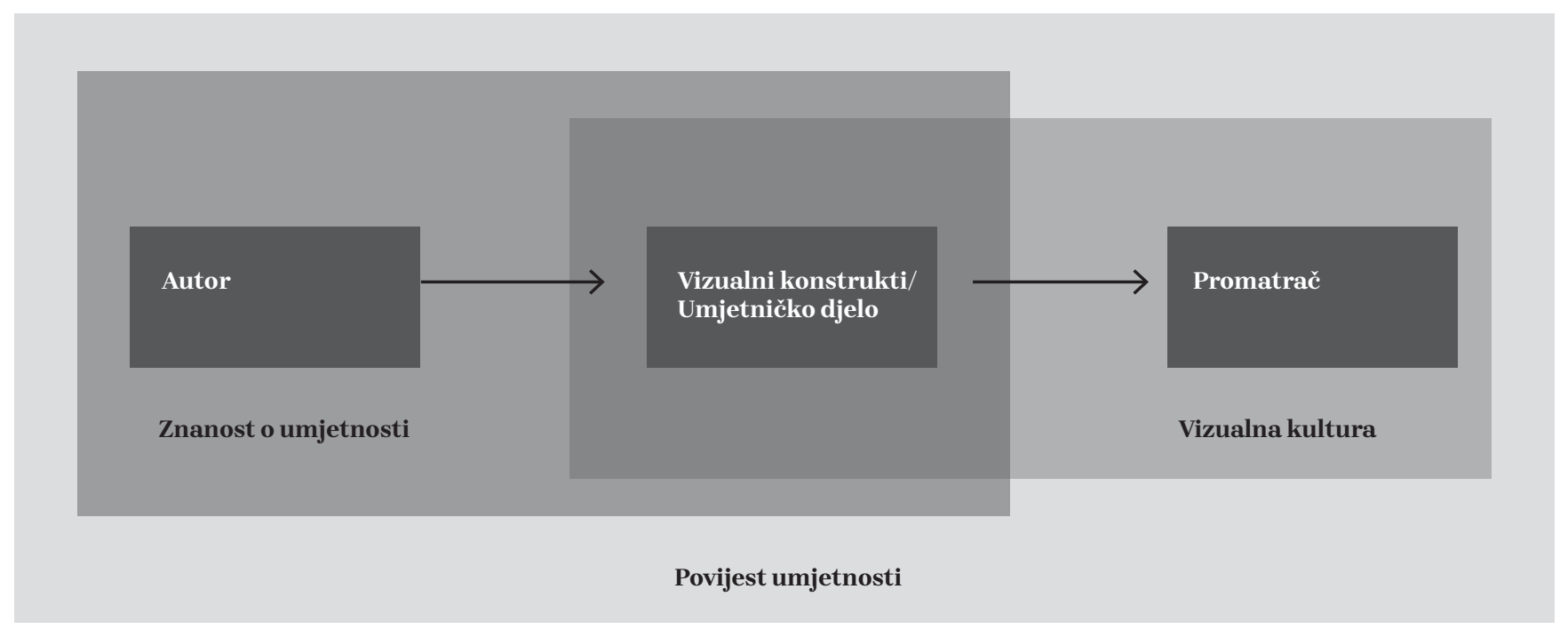

druge kontekste nastanka djela, dok se vizualna kultura bavi recepcijskim odnosima između vizualnih konstrukta i promatrača. Jedino povijest umjetnosti obuhvaća u istom komunikacijskom procesu potpunu trijadu baveći se prijenosom značenja od autora preko umjetničkog djela do promatrača, što je čini odličnom osnovom za razvoj promatračkih kompetencija. Temeljnim nedostatkom povijesti umjetnosti smatra se prevelika usmjerenost na objekt, za razliku od vizualne kulture, ponajprije usmjerene na subjekt, koji i jest u središtu obrazovnog sustava. Nakon šezdesetih godina 20. stoljeća povijest umjetnosti proširila je svoje predmetno područje pod utjecajem novih umjetničkih praksi, ${ }^{8}$ koje su se poslužile elementima popularne kulture i usvojile karakteristike vizualne reprezentacije iz različitih oblika kulturne proizvodnje. ${ }^{9}$ Takve epistemološke promjene objedinjene su nazivima kritička, nova i radikalna povijest umjetnosti jer se ne oslanjaju samo na povijesnoumjetničku, odnosno stilsku analizu, nego istražuju politički, umjetnički i ideološki kontekst nastanka djela, ${ }^{10}$ čime otvaraju vrata vizualnoj kulturi te proširuju svoje interese na receptivne sposobnosti promatrača.

\section{Kritički instrumentarij kompetentnog promatrača}

Suvremeno društvo teži razvoju kompetentna promatrača koji raspolaže razvijenim kritičkim oruđem i upotrebljava ga za proizvodnju značenja koje mu svakodnevno posreduju vizualni konstrukti iz njegove okoline. Metode takva kritičkog oruđa počele su se razvijati unutar povijesnoumjetničke hermeneutike, o čemu govori i činjenica da je pojam vizualne kulture upotrijebila Svetlana Alpers u studijama o nizozemskom slikarstvu I7. stoljeća u kojima način viđenja umjetničkih djela ne pripisuje vizualnim svojstvima medija nego kulturološkim
Slika I

Komunikacijski procesi unutar velike trijade

MARTIN WARNKE (bilj. 6), 22

LJILJANA KOLEŠNIK, Kritička povijest umjetnosti: perspektive i dometi, u: Umjetničko djelo kao društvena činjenica. Perspektive kritičke povijesti umjetnosti, (ur.) Ljiljana Kolešnik, Zagreb, Institut za povijest umjetnosti, 2005., 35I-400, 355 .

IO LJILJANA KOLEŠNIK (bilj. 9), 355 . 
okvirima razdoblja. ${ }^{11}$ Povijesnoumjetnička hermeneutika razvila se kao zbroj teorija i metoda za tumačenje umjetničkog djela. ${ }^{12}$ Problemi su interpretacije višestruki jer se recepcija umjetničkog djela najčešće događa s povijesnom distancom i kao sredstvo izražavanja koristi verbalni jezik, koji često ne može iskazati sve slojeve vizualnog sadržaja. Interpretacija se stoga smatra nepouzdanom jer je promatrač podložan kulturološkim uvjerenjima i podsvjesnim obrascima. Zbog toga su razvijene hermeneutičke metode, tj. formalna, stilska i ikonografsko-ikonološka analiza, koje pristupaju umjetničkom djelu s različitih aspekata. Formalnom analizom pristupa se formi kao sredstvu priopćenja, u kojem su svi interpretativni doživljaji i reakcije vezani za izvedbene i materijalne karakteristike medija koji ih nosi. Takav pristup rezultira dihotomijom forme i sadržaja jer se neki dijelovi sadržaja ne mogu otkrivati analizom forme. ${ }^{13}$ Stilskom analizom djelo se vraća u povijesni kontekst, ali se interpretira samo pripadnošću određenoj skupini oblika, što pak ne otkriva ništa o sadržaju koji ne proizlazi iz stilskih karakteristika djela. Ključne promjene $u$ istraživanju značenja ostvarene su ikonografsko-ikonološkom metodom koja umjetničko djelo istražuje u njemu suvremenu kontekstu uz pomoć svih dostupnih izvora. ${ }^{14}$ Funkcioniranje modela ikonografsko-ikonološke metode objasnio je Erwin Panofsky u tri stupnja koja čine jedinstven proces interpretacije: predikonografski opis, ikonografska analiza (znanje o povijesti umjetnosti i promjenama) i ikonološka interpretacija koja aktivno uključuje svjesne i nesvjesne asocijacije te promatračevo znanje u konstruiranju značenja. ${ }^{15}$ Promjenjivost značenja djela otvorila je putove semiotičkoj analizi koja proučava sve vizualne pojave bez obzira polažu li pravo na status umjetničkog djela, usmjeravajući se ponajprije na odnos između fiziologije oka i konvencija gledanja. ${ }^{16}$ Kritička povijest umjetnosti razvila je nove interpretativne strategije koje se više oslanjaju na kontekstualnu analizu unoseći u interpretaciju umjetnosti važnost sadašnjeg trenutka. ${ }^{17}$ Ti pristupi ne razmatraju kontekst samo kao povijesnu datost, nego ga tretiraju kao nestabilnu strukturu koja se mijenja ovisno o vremenima i uvjetima percepcije gledatelja. ${ }^{18}$

\section{Položaj povijesti umjetnosti u hrvatskom obrazovnom sustavu}

Povijest umjetnosti svoje je mjesto u srednjoškolskom obrazovnom sustavu zauzela predmetom Likovna umjetnost $u$ gimnazijskom obrazovanju te predmetom Povijest likovne umjetnosti u obrazovanju s područja vizualnih umjetnosti i dizajna. Koncept nastavnih jedinica u skromnijem obliku preslikao je program studija povijesti umjetnosti i nije se mijenjao od I96o. godine pa u prvoj godini učenici savladavaju osnove likovnog jezika, a od drugoga do četvrtog razreda sadržaji su organizirani na temelju povijesnih i stilskih razdoblja od prapovijesti do suvremenog doba. ${ }^{19}$ Kronološkim rasporedom nastavnih jedinica ističe se, dakle, isključivo povijesni kontekst
II KIM H. VELTMAN, Svetlana Alpers, The Art of Describing, Chicago: University of Chicago Press I983 [Review], u: Kunstchronik, München, 37, 7 (I984.), $262-267,267$.

I2 OSKAR BÄTSCHMANN, Upute za interpretaciju: povijesnoumjetnička hermeneutika, u: Uvod u povijest umjetnosti, (ur.) Hans Belting i dr., Zagreb, Fraktura, 2007., I8I-208, I8I.

I3 HERMANN BAUER, Forma, struktura, stil: povijest i metode formalne analize, u: Uvod u povijest umjetnosti, (ur.) Hans Belting i dr., Zagreb, Fraktura, 2007., I $43^{-}$I5 8 , I 47

I4 JOHANN KONRAD EBERLEIN, Sadržaj i smisao: ikonografsko-ikonološka metoda, u: Uvod u povijest umjetnosti, (ur.) Hans Belting i dr., Zagreb, Fraktura, 2007., I59- 79 , I6I.

I5 ALEKSANDAR MIJATOVIĆ, Vizualna kultura i kraj tumačenja slike ili kako predsubjektivna fascinacija postaje teorijom bez subjekta, u: Umjetnost riječi, I-2 (20I0.), , 83-IO4, 85 .

I6 LJILJANA KOLEŠNIK (bilj. 9), 387 .

I7 LJILJANA KOLEŠNIK (bilj. 9), 356 .

I8 LJILJANA KOLEŠNIK (bilj. 9), 389 .

I9 Kome treba kreativnost: Strategija razvoja kreativnosti u osnounoškolskom i srednjoškolskom odgoju $i$ obrazovanju, 2I, dostupno na: http://stari.dizajn.hr/ files/I67I_I_Kome\%2otreba\%2okreativnost.pdf (posjećeno I5. prosinca 20I6.) 
nastanka djela, koji se umjetničkim djelom bavi kao posljedicom društvenopovijesnih okolnosti, čime se zanemaruje stvaralačka vrijednost i semiotička kompleksnost komunikacije koja se uspostavlja između promatrača i umjetničkog djela. Od učenika se očekuje svladavanje povijesnoumjetničke hermeneutike, formalne, stilske i ikonografsko-ikonološke analize, koje primjenjuju u analizi djela, a konačni je cilj učenja predmeta određivanje povijesne pripadnosti umjetničkog djela. U takvu kurikulu zanemareno je kreativno i kritičko mišljenje, kao i mogućnost izravna povezivanja sličnih ili istovjetnih pojava u prošlosti i sadašnjosti. Nastavni program opterećen je velikim brojem propisanih umjetničkih djela koja pokrivaju sva povijesna i stilska razdoblja te većinu tradicionalnih i suvremenih medija i umjetničkih praksi. Satnica od trideset i pet sati po godini ne pruža pak dovoljno prostora za analitički pristup propisanim primjerima i refleksiju o djelu.

\section{Mogućnosti integracije vizualne kulture u kurikulum}

U postmoderno doba komunikacija u našem okolišu većinom se odvija posredovanjem slika, pa je sposobnost kritičkog propitivanja i razumijevanja funkcioniranja vizualnih znakova i simbola postala jedna od ključnih kompetencija, zbog čega vizualna kultura svakako mora postati dio kurikula. U svijetu su se zadnjih deset godina pojavili različiti prijedlozi uvođenja vizualne kulture u obrazovne sustave, a i sama disciplina povijest umjetnosti doživjela je epistemološke promjene koje otvaraju područje istraživanja prema sadržajima vizualne kulture. I u europskom i u američkom području javljaju se pritom dvije tendencije, od kojih jedna daje prijedloge integriranja sadržaja vizualne kulture u kurikul predmeta Likovna umjetnost, a druga zagovara promjenu imena predmeta u Vizualnu kulturu. Različiti načini organiziranja kurikula zahtijevaju različite koncepcije uspostavljanja veza između školskih predmeta i stvarnih životnih potreba. U posljednjih dvadeset godina većina europskih zemalja reformirala je okvirne nacionalne kurikule vođena holističkim pristupom polazeći od cjeline znanja, vještina i vrijednosti koje učenik razvija do kraja školovanja. ${ }^{20}$ Napušteno je određivanje nastavnog sadržaja planom i programom jer usmjerava učenje prema faktografskom znanju i smetnja je kreativnim oblicima nastave koji zahtijevaju slobodnije planiranje nastavnog procesa. Sadržaji i ishodi predmeta usmjeravaju se prema kompetencijama radi postizanja znanja potrebnih za život, a predmeti se međusobno povezuju u kurikulska područja međupredmetnim temama koje bi trebale usmjeriti nastavni proces na primjenu disciplinarnih znanja u interdisciplinarnom kontekstu. S obzirom na tradicionalnu strukturu hrvatskog obrazovnog sustava, u kojem su predmeti izvedeni iz znanstvenih disciplina te dodatno određeni planom i programom, korelativne veze uspostavljaju se uvođenjem spomenutih međupredmetnih tema. Zbog promjena obrazovnih i odgojnih paradigmi, koje sada teže povezivanju sadržaja osnovnih obrazovnih područja
20 BRANISLAVA BARANOVIĆ, Nacionalni kurikulum u europskim zemljama i Hrvatskoj: komparativni prikaz, u: Sociologija sela, 44 (2006.), I8I-200, I92. 
i predmeta s potrebama pojedinca u svakodnevnom životu, postavlja se pitanje koje vještine i znanja učenje likovne umjetnosti može razviti, a da se aktivno koriste u budućnosti. U takvu konceptu suočavanje s komunikativnim aspektima slike, koji nam posreduju značenja svaki dan, postalo je važna komponenta za razumijevanje svijeta oko nas. Odvajanje znanosti o slici od povijesti umjetnosti otvorilo je pak put mišljenju da u obrazovnim sustavima Likovnu umjetnost treba zamijeniti Vizualnom kulturom. Mehanička zamjena jednog predmeta drugim dovela bi pak do neopravdana „svojatanja” područja vizualne kulture, koje ima široke interdisciplinarne implikacije, ali i do banaliziranja čitanja umjetničkog djela, u kojem bi se izgubila stvaralačka komponenta samog djela. Promišljanje se vizualne kulture stoga ne treba događati isključivo unutar jedne discipline, nego se treba propitivati na razini međupredmetne integracije u sva područja kurikula. Uvođenjem vizualne kulture kao interdisciplinarne poveznice među različitim predmetima otvorio bi se put prema metakompetenciji vizualne pismenosti, ravnopravne verbalnoj pismenosti. $\mathrm{Na}$ taj bi način i predmet Likovna umjetnost dobio čvrste temelje za nužne konceptualne i metodičke promjene, ako ne radi osobne dobrobiti, onda radi nužnosti otvaranja prema sadržajima vizualne kulture. Sve kurikulske promjene obrazovnih sustava, kao i epistemološke promjene discipline, ukazuju na to da povijest umjetnosti treba biti malo manje povijest, a malo više umjetnost, jer će u protivnom potpuno nestati iz obrazovnih sustava.

\section{(ㅇ) (1)}

Suživot vizualne kulture i povijesti umjetnosti: vizualna kultura kao međupredmetna tema/Lana Skender/CC BY / 4.0

DOI: https://doi.org/Io.3r664/z4khpu.25 